\section{History of Ultrasound}

Just to summarize in a few words that in 1972, the delegates of 13 European ultrasound societies met in Basel, Switzerland for the formal foundation of the European Federation of Societies for Ultrasound in Medicine and Biology (EFSUMB). Today the Federation comprises 29 National Societies with 21000 members, which means EFSUMB is the largest Society within the World Federation for Ultrasound in Medicine and Biology (WFUMB). The European Federation's purpose has been to promote the exchange of scientific knowledge in the field of ultrasound. EFSUMB aims are served by arrangement of congresses, meetings and courses at an international level, as well as the exchange of information both in and outside Europe by the member organizations (Dietrich CF, Rudd L, 2013; Dietrich CF et al., 2017).

EFSUMB in general has aimed to enrich the ultrasound community with updated material on many aspects of ultrasound. History of ultrasound details may be forgotten soon since so many pioneers have been passing away and with them the detailed know- ledge of the first scanners, congresses and meetings by competition and friendship. EFSUMB is aware that this is the right time to reflect and illustrate the achievements of European Ultrasound. EFSUMB has strengthened the interdisciplinary collaboration in the field of diagnostic ultrasound and promoted safety of ultrasound in medical use and most recently started a project on EFSUMBs History of Ultrasound

- To summarize the history of ultrasound from the very beginning up to the introduction of the most recent technologies of contrast enhanced ultrasound and elastography.

- To present the very beginning and advances of ultrasound technology.

- To present the pioneers and their important followers.

- To present most important references.

- To present important events (congresses).

- To present illustrative images of the pioneers and technologies.

- To present the convergence and divergence of various ultrasound disciplines.
One of the main objectives is to give the EFSUMB member societies a platform to present their impressive achievements. Over the next month EFSUMB will collect the information of member societies on the EFSUMB website. We might finally achieve a book, e-book or at least an app of all this important information.

Please consider contributing with facts, photos and memories of our beautiful method under the principle "when art meets the history of ultrasound science".

Christoph F Dietrich

EFSUMB Past President 2013 - 2015

\section{References}

1. Dietrich CF, Rudd L. The EFSUMB website, a guide for better understanding. Med Ultrason 2013; 15: 215 - 223.

2. Dietrich CF, Rudd L, Saftiou A, Gilja $\mathrm{OH}$. The EFSUMB website, a great source for ultrasound information and education. Med Ultrason 2017; 19: 102 - 110. 